\title{
A Longitudinal Study for the Relationship between Motor Coordination and Body Mass Index in Primary School Children
}

\section{Dimitra Doloma}

Department of Physical Education \& Sport Science, Democritus University of Thrace, Greece,dimdoloma@gmail.com

\section{Antonios Kambas}

Prof., Department of Physical Education \& Sport Science, Democritus University of Thrace, Greece, akampas@phyed.duth.gr

\section{Nikolaos Aggeloussis}

Prof., Department of Physical Education \& Sport Science, Democritus University of Thrace, Greece,nagelous@phyed.duth.gr

\section{Maria Michalopoulou}

Prof., Department of Physical Education \& Sport Science, Democritus University of Thrace, Greece,michal@phyed.duth.gr

The purpose of the present study was to examine: a. the development of primary school students' motor coordination (MC) within three years, b. gender as a crucial factor of this development, c. the relationship between MC and Body Mass Index (BMI). Students' performances as well as the BMI of 20 boys and 22 girls were measured throughout a three-year period. Students' MC was evaluated with Körperkoordination Test für Kinder (KTK) a test with four subtests in order to evaluate Motor Coordination (MC) of 5-14-year-old children. Results indicated that: a. the MC increased during the two first years of program $b$. that there was a negative correlation between BMI and KTK results/every year: Increases in BMI were correlated with decreases in a rating of KTK results/every year c. there was a statistically significant interaction between motor coordination and BMS. From the analysis of the results and the discussion that followed we came to the following conclusions: a. the participation in organized physical activities could help students who were at the first and second class to improve-develop their motor coordination, $b$. the increase in body mass index had a negative impact on the size of children's knee joints, c. the body mass index can successfully predict the extent of the knee joint and the gender of the boys contributed to this prediction.

Keywords: fine \& gross motor abilities, obesity, physical activity, primary school, child

Citation: Doloma, D., Kambas, A., Aggeloussis, N., \& Michalopoulou, M. (2020). A Longitudinal Study for the Relationship between Motor Coordination and Body Mass Index in Primary School Children. International Journal of Instruction, 13(3), 511-524. https://doi.org/10.29333/iji.2020.13335a 


\section{INTRODUCTION}

The modern sedentary lifestyle and lack of physical activity in children and adolescents is a major problem since chronic diseases in adults such as heart disease, type II diabetes and obesity appear in childhood (Tzetzis, Kakamoukas, Goudas, \& Tsorbatzoudis, 2005). Concerned by Greek society (Tokmakidis, Bogdanis, Sindonis, Mougios, \& Mamen, 2000) and the global community, the lack of physical activity due to low levels of physical activity in the world and the ensuing poor eating habits (Laukkanen, Pesola, Finni, \& Sääkslahti, 2017), which has doubled in the last 20 years among young people (children and adolescents) (Center for Disease Control and Prevention, 2004).

Trost, Kerr, Ward, and Pate (2001), recorded the participation, both in intense and moderate physical activity, of 133 high school students $(11.4 \pm 0.6)$ with normal BMI and 54 obese pupils. Their results showed that obese children had statistically lower daily and weekly physical activity. Janssen, Katzmaryk, Boyce, Vereeken, Mulvihill, Vereeken, Mulvihill, Roberts, Currie, and Picket (2005) examined the incidence of obesity among students in 34 countries and a sample of 137,593 children aged 6 to 16 years and found that in countries where youth physical activity is low and children watch television for several hours, mobility levels increase and obesity is increased.

In Greece, the Greek Obesity Medical Society (2005), with a sample of 18,045 children and adolescents, found that at the age of 7 to 12 years, $12.7 \%$ of boys and $11.1 \%$ of girls are overweight, while the corresponding figures for the $10 \%$ and the $7.2 \%$ of adolescents are obese (13-19 years), the $20.7 \%$ of boys are overweight while the $8.9 \%$ are obese. Among girls, over the $12.5 \%$ is considered overweight and $3.6 \%$ obese. In their research, Tzetzis, Kakamoukas, Goudas, and Tsorbatzoudis, (2005) examined the physical activity of 35 non-obese and 34 obese first-year students using the CSA accelerometer for four days. The results showed that obese children had statistically less daily physical activity and participated in little moderate exercise and almost no intense exercise.

The survey results reveal beneficial benefits for the physical, mental and psychological health and well-being of children and adolescents who participate in regular physical activity (Hagger, Chatzisarantis, \& Biddle 2001). According to a report by the US Department of Health, "physically active people are living longer and have a lower incidence of disease" (US Department of Health and Human Services, 2001). Researchers in the fields of public health, epidemiology, and physical education emphasize the importance of systematic participation in health promotion exercises (Martin \& Kullina, 2004).

Physical education classes play an important role in the physical, mental and mental health and well-being of students. According to Kioumourtzoglou and Derri (2003), physical education is the only area of the school curriculum that is directly related to health status, aims to form behaviours, improves self-esteem and positively affects a number of parameters of students' character and personality. The purposes of the physical education course are manifold and concern the psychomotor, emotional, cognitive and social development of the child (Bournelli, Koutsouki, Zografou, 
Maridaki, Chatzopoulos, and Agalianou, 2007). The ultimate goal of this lesson is to increase children's overall physical activity and to develop attitudes and behaviours towards physical education that will enable children to exercise and play sport throughout their lives (Alderman, Beighle, \& Pangrazi, 2006). Physical education lessons, in addition to learning motor skills, promotes students' health by providing them with knowledge and making them active in a society characterized by subjectivity and lack of physical activity. Childhood obesity is a growing problem (AGA, 2004; Kavey, Daniels, Lauer, Atkins, Hayman, \& Taubert, 2003). School and physical education lessons can play an important role in students' health and commitment to physical activity. Participation in physical activity from an early age contributes significantly to the acquisition and construction of a healthy skeletal system, develops muscle strength and endurance, reduces the risk of chronic disease, strengthens the body, and reduces stress (Physical Activity Guidelines, 2008).

Participation in Physical Education, which improves children's physical activity, leads to the improvement of their kinetic abilities lessons (Cools, De Martelaer, Samaey, and Andries, 2010). Children with developed levels of kinetic ability, compared to their classmates of the same age, have a higher average rate of participation in Physical Education programs (Schott, Alof, Hultsch, and Meermann, 2007). Surveys have shown that children who do not participate in physical activity programs inside and outside school have lower motor skills and high BMI, meaning they are overweight and obese (Stodden, Langendorfer, and Roberton, 2009). As a result, D' Hondt et al. (2011) surveyed of 954 students aged 5 to 12 years to investigate the relationship between the kinetic assembly and body mass index. The survey results revealed that students with good kinetic alignment have a normal body mass index in both boys and girls and systematically participate in organized physical activity programs. D' Hondt, Deforche, Gentier, De Bourdeaudhuij, Vaeyens, Philippaerts, and Lenoir (2013), based on a sample of 712 students from 13 schools in Belgium, argued that the cumbersome kinetic assembly of obese and overweight children is significantly lower than that of their peers with normal weight. The researchers noted that the evolution of the level of motor coordination and the improvement of motor skills is statistically significant with the weight status of children and especially with obesity. Mond et al. (2007) surveyed students aged 4.5 to 8.5 years on the role of obesity in children's kinetic development. The researchers argued that lack of motor performance was more evident in obese boys than in boys of normal weight. Graf et al. (2005) studied the impact of the Children's Health Interventional Trial (CHILT) program, which combines increased participation in physical activity and student education on the health, body mass index and motor skills of students aged 5.5 to 9 years. The study was 2 years in duration and measurements were taken in the fall of the $1^{\text {st }}$ year and the spring of the $2^{\text {nd }}$ year. Research results showed that motor performance improved statistically in the experimental group.

From what has been mentioned above, it is clear that there is no survey to examine the impact of physical activity participation during the school program on improving the motorization of first-year students. Thus, the purpose of this document was: a. to study: a. the improvement of the motor coordination of students attending primary school 
within three years through participation in physical activities; b. gender as a differentiating factor in this development; and $\mathrm{c}$. the increasing relationship between the motor coordinator and body mass index.

The questions asked to answer the survey are:

a. If participation in organized physical activities contributes to the improvement of the motor coordinator.

b. If there is a correlation between the motor coordinator and the body mass index.

c. If gender is a factor of differentiation of motor coordinator.

\section{METHOD}

\section{Subject}

The survey covered one hundred (100) students attending the first grade of primary schools in the city of Komotini. The selection of students who participated in the survey was made following a random selection of schools, where the survey would have taken place. A basic prerequisite for the school's participation in the research was that physical education teachers should be permanent ones and remain in the school for the next four school years. Students were then asked to participate in physical activities organized in their school at least three times a week, and of the respondents, 50 boys and 50 girls were selected by random draw. Twenty boys and 22 girls participated in the final survey, 58 of whom dropped out of the survey for personal reasons such as reluctance to participate in the research in the second year of research, change in the school environment, family relocation or absence from most research due to health problems.

\section{Procedure}

Before the survey was launched, a meeting was held with the teachers who then implemented the program, during which they explained the research objectives and the entire research process. It was mentioned that their participation requires their training in measuring instruments and their use. On behalf of the teachers, questions were asked about the organization and conduct of the research as a whole, as well as about whether or not students were required to participate in it.

As mentioned above, the first step of the survey was the training of teachers invited to implement the program. The training took place over a period of 10 months, from September 2012 to May 2013, and included the demonstration and use of measuring instruments and internships in these instruments. The program included two measures, at the beginning and end of each school year, of anthropometric characteristics and the quality test for overall neuromuscular coordination (KTK).

With respect to student participation in the program, parents/guardians were informed and after the program objectives were explained in detail and they were assured that participation in the research was voluntary and that they could leave at any time and that the research results would be anonymous and would be used solely for research 
purposes, they were asked to give their written permission for the student to participate in the program

\section{Data collection}

Data collection included:

a. anthropometric measurements: The somatometric characteristics measured were height, using a $1 \mathrm{~cm}$ scale, and weight, using a precision balance $(0.1 \mathrm{~kg})$ to calculate the body mass index $\left(\mathrm{BMI}=\right.$ weight $/$ height $\left.^{2}\right)$. BMI is used to assess the body composition of adults and children (Chumlea, Knittle, Roche, Siervogel, \& Webb, 1981). Waist and hip circumference and tibia length were also measured. The limits proposed by the IOTF (Cole, Bellizzi, Flegal, \& Dietz, 2000) were used to classify students into normal, overweight and obese weight classes.

Table 1

Means \& Standard Deviation Boys' Anthropometric Measurements in 6 Measures (boys)

\begin{tabular}{|c|c|c|c|c|c|c|}
\hline \multirow[t]{3}{*}{ Boys } & \multicolumn{4}{|c|}{ Measures } & \multirow{2}{*}{\multicolumn{2}{|c|}{$3^{\text {rd }}$ class }} \\
\hline & \multicolumn{2}{|c|}{$1^{\text {st }}$ class } & \multicolumn{2}{|c|}{$2^{\text {nd }}$ class } & & \\
\hline & $1^{\text {st }}$ & $2^{\text {nd }}$ & $1^{\mathrm{st}}$ & $2^{\text {nd }}$ & $1^{\text {st }}$ & $2^{\text {nd }}$ \\
\hline Age & $75.7 \pm 3.1$ & $82.7 \pm 3.1$ & $87.7 \pm 3.1$ & $94.7 \pm 3.1$ & $99.7 \pm 3.1$ & $106.7 \pm 3.1$ \\
\hline Height & $119.3 \pm 5$ & $120.9 \pm 5.6$ & $124.1 \pm 5.6$ & $128 \pm 5.1$ & $131.8 \pm 5.7$ & $136.6 \pm 4.7$ \\
\hline Weight & $22.3 \pm 4.5$ & $25.6 \pm 5.1$ & $27.4 \pm 5.3$ & $29 \pm 6.1$ & $30.7 \pm 6.9$ & $32.3 \pm 8.3$ \\
\hline BMI & $15.5 \pm 2.2$ & $17.4 \pm 2.7$ & $17.7 \pm 2.7$ & $17.5 \pm 3$ & $17.6 \pm 3.4$ & $17.1 \pm 3.8$ \\
\hline
\end{tabular}

Tables 1 and 2 present the students' anthropometric characteristics and the 6 measures, while Table 3 presents the annual means.

Table 2

Means \& Standard Deviation Girls' Anthropometric Measurements in 6 Measures (girls)

\begin{tabular}{|c|c|c|c|c|c|c|}
\hline \multirow[t]{3}{*}{ Girls } & \multicolumn{6}{|c|}{ Measures } \\
\hline & \multicolumn{2}{|c|}{$1^{\text {st }}$ class } & \multicolumn{2}{|c|}{$2^{\text {nd }}$ class } & \multicolumn{2}{|c|}{$3^{\text {rd }}$ class } \\
\hline & $1^{\mathrm{st}}$ & $2^{\text {nd }}$ & $1^{\mathrm{st}}$ & $2^{\text {nd }}$ & $1^{\mathrm{st}}$ & $2^{\text {nd }}$ \\
\hline Age & $75.8 \pm 3$ & $82.8 \pm 3$ & $87.7 \pm 3$ & $94.7 \pm 3$ & $99.8 \pm 3$ & $106.8 \pm 3$ \\
\hline Height & $121.4 \pm 5.4$ & $122.8 \pm 5.2$ & $125.5 \pm 6$ & $129.3 \pm 4.9$ & $133.7 \pm 4.8$ & $137.6 \pm 4.6$ \\
\hline Weight & $25 \pm 5.4$ & $28.7 \pm 5.7$ & $30.4 \pm 6.4$ & $32.2 \pm 6.7$ & $35 \pm 7$ & $35.1 \pm 7.5$ \\
\hline BMI & $16.8 \pm 2.9$ & $18.9 \pm 2.8$ & $19.2 \pm 3.1$ & $19.1 \pm 3.2$ & $19.5 \pm 3.2$ & $18.3 \pm 3.3$ \\
\hline
\end{tabular}

As illustrated in Table 3, first-grade boys are slightly weighted normal while the girls are overweight. In the second year, boys are again of normal weight and the girls are overweight, whereas in the third year, boys are of normal weight and girls are slightly overweight. More specifically, in the first class, 17 boys and 13 girls were at a normal weight, 2 boys and 7 girls were overweight and 1 boy and 2 girls were considered obese. In the second year, 12 boys and 8 girls are classified as of normal weight, 5 and 8 as overweight and 3 and 6 as obese. Finally, in the third year, 12 boys and 9 girls are classified as having a normal weight, 5 and 6 are overweight and 3 boys and 7 girls are considered obese. 
Table 3

Means \& Standard Deviation of Anthropometric Measurements Per Class

\begin{tabular}{lllllll}
\hline Students & 1st class & \multicolumn{3}{c}{ 2nd class } & 3rd class \\
\hline & Boys & Girls & Boys & Girls & Boys & Girls \\
\hline Age & $79.2 \pm 3.1$ & $79.3 \pm 3$ & $91.2 \pm 3.1$ & $91.3 \pm 3$ & $103.2 \pm 3.1$ & $103.3 \pm 3$ \\
Height & $120.1 \pm 5.3$ & $122.1 \pm 5.2$ & $126.6 \pm 5.3$ & $127.2 \pm 5.3$ & $134.7 \pm 5.1$ & $135.7 \pm 5$ \\
Weight & $23.9 \pm 4.6$ & $26.8 \pm 5.5$ & $28.2 \pm 5.7$ & $31.3 \pm 6.6$ & $31.5 \pm 7.5$ & $35.1 \pm 7.1$ \\
BMI & $16.5 \pm 2.4$ & $17.9 \pm 2.8$ & $17.6 \pm 2.8$ & $19.2 \pm 3.2$ & $17.3 \pm 3.6$ & $18.9 \pm 3.2$ \\
\hline
\end{tabular}

b. Evaluation of motor coordination

The Körperkoordinationstest für Kinder (KTK test battery) by Kiphard and Schilling (2007) was used to assess students' motor coordination, including:

1. Evaluating balance ability - walking on a balance beam backwards: The tested person should balance, walking backwards, along three beams 3 meters long and 6, 4.5 and 3 $\mathrm{cm}$ respectively. The number of steps on the beam is recorded until one foot is in touch with the ground or eight (8) steps are reached. If there is a loss of balance (contact between foot and ground) in the test effort, the effort continues until the end of the beam. In case of loss of balance in normal attempts, execution is interrupted and the next attempt of the same (2nd and 3rd attempt) or another beam starts immediately, from the starting point, namely the address surface.

The step counting starts from the moment that the second foot is placed on the beam. The highest performance recorded is eight (8) steps. However, even if more than 8 valid steps are performed, only eight (8) are recorded. For each beam, the sum of the three (3) performances is calculated. The maximum score for each beam is 24 step points (3 attempts $\times 8$ steps/effort). The maximum score for this competency is 72 steps - points (3 beams x 24 steps-notes/beam).

2. Jumping skills: The materials required to perform the measurement are 12 hurdles of rectangle sponges of $50 \mathrm{~cm}$ length, $20 \mathrm{~cm}$ width and $5 \mathrm{~cm}$ height each. The examiner, after taking a range (about $1.50 \mathrm{~m}$ ), jumps with one leg over a hedge, the height of which changes. Immediately after landing, it must continue with at least two bounces on the supporting leg. The record for each height and effort is as follows: For the $1^{\text {st }}$ successful round, 3 points are scored, for the $2^{\text {nd }}$ attempt 2 points and the $3^{\text {rd }}$ attempt 1 point. After a first successful attempt at execution from a starting height of $5 \mathrm{~cm}, 3$ points are awarded for each previous height. An attempt is considered unsuccessful when the oscillating foot is in contact with the ground, moving the obstacle during the jump or less than 2 bounces after landing. Failure in all three attempts at a certain height means that the effort must be stopped. Efforts will only continue if the two previous heights have reached a total of 5 points. The above applies separately for each leg. The maximum result that can be obtained for each foot is 36 points, and a total of 72 points for both legs.

3. Ability to quickly move the body with lateral jumps: The materials required for the measurement are a rectangular wooden surface of $100 \mathrm{~cm}$ wide, $60 \mathrm{~cm}$ long and $3 \mathrm{~cm}$ thick, divided in two by $\mathrm{a} 60 \times 3 \times 3 \mathrm{~cm}$ bar. The test-man performs oblique jumps to the 
right and left over the separation bar with both legs joined for 15 seconds. Note the number of valid lateral jumps (right $=1$, left $=2$ ) of two $(2)$ valid attempts of 15 seconds each. As a final result, we add the number of valid jumps of the two (2) attempts.

4. Side-by-side movement and repositioning (ITM): The materials required to perform the measurement are two $20 \mathrm{~cm} \times 20 \mathrm{~cm} \times 20 \mathrm{~cm} \times 2 \mathrm{~cm}$ square wooden constructions, with rounded corners, where under each corner is screwed a rubber base $3.7 \mathrm{~cm}$ high. The examiner moves with both legs on a square plate - one surface, folds, takes the second in his hands, places it next to others and pushes it with both legs. Then he takes the surface on which he was originally moved, put sit back next to the other and presses it down. The process takes 20 seconds. The number of surface movements and their placement over 20 seconds is recorded. When the surface to the right of the child is placed on the left, we measure 1 and when the child is placed with both feet on the surface we measure 2 . The scores of each effort are recorded and then summed.

According to Vandorpe, Vandendriessche, Lefevre, Pion, Vaeyens, Matthys, Philippaerts, and Lenoir (2011), the KTK is an appropriate tool for assessing severe motor coordinator in children aged 5 to 14 years. According to the same researchers, the bundle is a useful tool for detecting sports talent and especially talent that could become among elite athletes in the gym (Vandorpe, Vandendriessche, Vaeyens, Pion, Matthys, Lefevre, Philippaerts, \& Lenoir, 2012). Moreover, it helps to assess the quality and development of motor coordinator, diagnose motor problems that are not evident in daily life, identify kinetic deficits due to brain damage and, finally, determine the degree of intelligence or kinetic damage in children with special needs.

The KTK score of each of the four tests is converted into a kinetic quotient (MQ) according to which 131 to 145 points is considered very good kinetic performance, 116 to 130 points good, 86 to 115 points normal, 71 to 86 there is motor dexterity and finally 56 to 70 points the person has a kinetic disorder (Kiphard and Schilling, 2007).

\section{Statistical analysis}

The following statistical analyses were carried out:

1) Descriptive statistics,

2) Reliability analysis,

3) Repeated Measures ANOVA,

4) Pearson Correlation analysis and

5) Regression analysis.

\section{FINDINGS}

\section{Repeated Measures for Each Class Separately}

The Repeated measures ANOVA analysis was applied for the "KTK $1^{\text {st }}$ class" factor. The analysis model (2X2) included the variable "measurement" (initial - final) as the repetition variable and the variable "gender" (boys - girls) as the independent variable. 
The results showed that there was a statistically significant interaction between the variable "measurement" for the "KTK $1^{\text {st }}$ class" $\left[\mathrm{F}_{(1,40)}=53.19, \mathrm{p}<.001, \mathrm{PES}=.57\right]$. The interaction analysis, with the use of the multiple comparison test (Post Hoc Bonferroni), showed that the sample had a statistically significant improvement after the end of the program (table 4).There was not a statistically significant interaction between boys and $\operatorname{girls}\left[\mathrm{F}_{(1,40)}=2.79 \mathrm{p}>.05\right]$.

Table 4

Initial \& Final Measurement for Every Class

\begin{tabular}{lllll}
\hline KTK & Measurement & $\mathrm{M}$ & $\mathrm{SD}$ & Measurement Interaction \\
\hline \multirow{2}{*}{$1^{\text {st }}$ class } & Initial & 80.55 & 12.20 & $\mathrm{~F}_{(1,40)}=53.19 ; \mathrm{p}<.001 ; \eta^{2}=.57$ \\
\cline { 2 - 4 } & Final & 91.5 & 16.12 & \\
\hline $2^{\text {nd }}$ class & Initial & 94.98 & 14.86 & $\mathrm{~F}_{(1,40)}=33.53 ; \mathrm{p}<.001 ; \eta^{2}=.46$ \\
\cline { 2 - 4 } & Final & 102.71 & 16.91 & \\
\hline \multirow{2}{*}{$3^{\text {rd }}$ class } & Initial & 98.29 & 15.57 & $\mathrm{~F}_{(1,40)}=.004 ; \mathrm{p}>.05 ; \eta^{2}=.00$ \\
\cline { 2 - 4 } & Final & 98.21 & 18.20 & \\
\hline
\end{tabular}

The Repeated measures ANOVA analysis was applied for the "KTK $2^{\text {nd }}$ class" factor. The analysis model (2X2) included the variable "measurement" (initial - final) as the repetition variable and the variable "gender" (boys - girls) as the independent variable. The results showed that there was a statistically significant interaction between the variable "measurement" for the "KTK $2^{\text {nd }}$ class" $\left[\mathrm{F}_{(1,40)}=33.53\right.$, $\left.\mathrm{p}<.001, \mathrm{PES}=.46\right]$. The interaction analysis, with the use of the multiple comparison test (Post Hoc Bonferroni), showed that the sample had a statistically significant improvement after the end of the program at the second class (table 4). There was not a statistically significant interaction between boys and girls $\left[\mathrm{F}_{(1,40)}=.401 \mathrm{p}>.05\right]$.

The Repeated measures ANOVA analysis was applied for the "KTK $3^{\text {rd }}$ class" factor. The analysis model (2X2) included the variable "measurement" (initial - final) as the repetition variable and the variable "gender" (boys - girls) as the independent variable. The results showed that there was not a statistically significant interaction between the variable "measurement" for the "KTK $3^{\text {rd }}$ class" $\left[\mathrm{F}_{(1,40)}=.004, \mathrm{p}>.05\right]$ (table 4). There was not a statistically significant interaction between boys and girls $\left[\mathrm{F}_{(1,40)}=.401 \mathrm{p}>.05\right]$.

\section{Repeated Measures for Total/Three Classes}

The Repeated measures ANOVA analysis was applied for the «KTK» total/three classes. The analysis model (3X2) included the variable "measurement" (first, second \& third measurement/class) as the repetition variable and the variable "gender" (boy-girl) as the independent variable. The results showed that there was a statistically significant interaction between the variable "measurement" for the «KTK» total/three classes $\left[\mathrm{F}_{(2,80)}=55.36, \mathrm{p}<.001 \& \mathrm{n}^{2}=.58\right]$. The interaction analysis, with the use of the multiple comparison test (Post Hoc Bonferroni), showed that the sample in the first year had the worst result while there was not a statistically significant interaction between the second and third years (table 5). There was not a statistically significant interaction between boys and girls $\left[\mathrm{F}_{(2,80)}=1.23, \mathrm{p}>.05\right]$ (table 5 ). 
Table 5

Measurement Interaction between the Three Classes

\begin{tabular}{|c|c|c|c|c|c|c|c|}
\hline $\begin{array}{l}\text { KTK } \\
\text { class }\end{array}$ & Total & SD & $\begin{array}{l}\text { Measurement } \\
\text { Interaction }\end{array}$ & Gender & $\bar{M}$ & SD & $\begin{array}{l}\text { Measurement } \\
\text { Interaction }\end{array}$ \\
\hline $1^{\text {st }}$ & 86.02 & 13.42 & \multirow{6}{*}{$\begin{array}{l}F_{(2,80)} \\
=55.36 ; p<.001 ; \\
\eta^{2}=.58\end{array}$} & Boy & 88.43 & 14.33 & \multirow{6}{*}{$\begin{array}{l}\mathrm{F}_{(2,80)} \\
=1.21 ; \mathrm{p}>.05 ; \\
\eta^{2}=.03\end{array}$} \\
\hline & & & & Girl & 83.84 & 12.47 & \\
\hline \multirow[t]{2}{*}{$2^{\text {nd }}$} & \multirow[t]{2}{*}{98.85} & \multirow[t]{2}{*}{15.33} & & Boy & 99.03 & 1680 & \\
\hline & & & & Girl & 98.68 & 14.26 & \\
\hline \multirow[t]{2}{*}{$3^{\text {rd }}$} & \multirow[t]{2}{*}{98.25} & \multirow[t]{2}{*}{16.49} & & Boy & 99.38 & 12.38 & \\
\hline & & & & Girl & 97.23 & 17.44 & \\
\hline
\end{tabular}

\section{Correlation Analysis}

A Pearson product-moment correlation coefficient was computed to assess the relationship between the amount of student Body Mass Index (BMI) and KTK results/every year. Results indicated that there was a negative correlation between BMI and KTK results/every year. Increases in BMI were correlated with decreases in the rating of KTK results/every year (Table 6).

Table 6

Bivariate Correlations among KTK Results/Every Year and BMI

\begin{tabular}{llll}
\hline KTK & BMI & & \\
\hline & Pearson Correlation & Sig. (2- tailed) & $\mathrm{N}$ \\
\hline $1^{\text {st }}$ class & $-.384^{* *}$ & $\mathrm{p}<.05$ & 42 \\
\hline $2^{\text {nd }}$ class & $-.424^{* *}$ & $\mathrm{p}<.001$ & 42 \\
\hline $3^{\text {rd }}$ class & $-.411^{* *}$ & $\mathrm{p}<.001$ & 42 \\
\hline
\end{tabular}

\section{Regression Analysis}

From the results of regression analysis it seems that the motor coordination has statistically significant interaction with BMS only for the boys of the sample for all years. For the total of the sample, it seems that there was a statistically significant interaction between motor coordination and BMS (table 7).

Table 7

Regression Linear Analysis for Motor Coordination \& BMI

\begin{tabular}{llllllllll}
\hline Year & \multicolumn{4}{c}{ Boys } & Girls & \multicolumn{2}{c}{ Total } \\
\hline & $\mathrm{R}^{2}$ & $\mathrm{f}$ & $\mathrm{p}$ & $\mathrm{R}^{2}$ & $\mathrm{f}$ & $\mathrm{p}$ & $\mathrm{R}^{2}$ & $\mathrm{f}$ & $\mathrm{p}$ \\
\hline $1^{\text {st }}$ year & .19 & 4.70 & $<.05$ & .109 & 2.46 & $>.05$ & .15 & 7.05 & $<.05$ \\
\hline $2^{\text {nd }}$ year & .291 & 7.40 & $<.05$ & .133 & 3.07 & $>.05$ & .194 & 9.60 & $<.05$ \\
\hline $3^{\text {rd }}$ year & .23 & 5.80 & $<.05$ & .032 & .666 & $>.05$ & .10 & 4.05 & $<.05$ \\
\hline
\end{tabular}

\section{DISCUSSION}

According to the survey results, in terms of body mass index, it appears that the firstclass sample has a significant percentage of children $(28.57 \%$ ) whose weight is above normal, while in the second and third classes the percentage of children exceeding normal weight is $52.38 \%$ and $50 \%$ of the total sample. The results of the study are consistent with other studies that indicate high rates of overweight and obesity in children (Afthentopoulou, 2018; Hassapidou et al, 2017; Kyriazis et al, 2012). 
As for the influence of participation in organized physical activities, it seems to contribute positively to the improvement of motor coordinator. Thus, in the first and second classes, the sample significantly improved its performance in all four beam tests. However, in the third year, student performance did not improve. Concerning the evolution of kinetic splicing, there is an improvement from the first to the second while there seems to be stagnation between the second and the third. The survey results appear to be partially consistent with other surveys (Lopes, Rodrigues, Maia, \& Malina, 2011; Starosta \& Hirtz, 1989), confirming that early school age is the appropriate age to improve the motor coordinator. The results of the survey show that gender is not a factor of differentiation and the changes observed in motor coordination are due both boys and girls. The results of survey contradict the results of Holfelder and Schott (2014) as well as Laukkanen, Pesola, Finni and Sääkslahti (2017) and according to which boys benefit more from girl.

As the results of the study have demonstrated, obesity appears to affect the motor coordinator, with overweight students exhibiting lower kinetic performance than their normal classmates. The results of this study are consistent with the results of similar studies that have examined the kinetic relationship between BMI and the ability to perform motor skills between norm bar children and obese or overweight children (Cheng et al., 2016; D' Hondt et al., 2013; D' Hondt et al., 2011; Graf et al., 2005; Marmeleira et al., 2017; Mond et al. 2007; Ruzbarska, Zvonar, Oleśniewicz, Markiewicz-Patkowska, Widawski, Puciato, 2016). The percentage (28\%) of overweight/obese children in this research corresponds to the high incidence of childhood obesity and requires drastic measures to treat and prevent it. The correlation is negative, which means that when the body mass index increases, children's motor coordinator decrease. This means that sedentary lifestyles and physical inactivity result in overweight children and a deficit in motor coordinator.

The results of regression analysis show that BMI appears to be a prediction factor of MC, especially in boys. This means overweight children will be adults with reduced MC. Or, reduced physical activity in childhood results in overweight adults and probably with many health problems. Similarly to the results of our study D' Hondt et al. (2014) and Laukkanen, Pesola, Finni and Sääkslahti (2017) that childhood overweight and obesity significantly contributed to a lower level of motor abilities as adults.

\section{CONCLUSION}

The results of the survey and the ensuing discussion led to the following conclusions.

a. Participation in organized physical activities can help improve the motor coordination of first-year students.

b. The increase in body mass index (obese and overweight children) has a negative impact on the size of children's motor coordinator.

c. The body mass index can successfully predict the motor coordination and the gender of the boys contributes to this prediction. 


\section{SUGGESTIONS FOR PRACTICAL APPLICATIONS}

Children spend about half of their day in school, which allows them to develop their motor skills without any cost, which are important for their entire lives, and to educate them for a lifelong lifestyle. The PE lesson plays an important role in childhood and should be available every day in the school program. One of the main objectives of the physical education course is to promote physical activity throughout life. School-based physical education classes could play an important role in promoting students' systematic participation in physical activity for exercise, physical and mental health and well-being. Motor coordination is one of the critical factors for athlete development, the foundations of which are in the school years and perhaps even much earlier.

Therefore it is recommended that PE teachers of primary schools should be particularly cautious about the weight of their pupils. They will have to diagnose their pupils' trends for extra kilos and their non-participation in the physical education lesson. They should attract the interest of their pupils so that participate actively in the course with ultimate aim of developing habits for lifelong sports.

\section{REFERENCES}

Afthentopoulou, A., \& Venetsanou, F. (2018). Body mass index and physical activity participation in 6-9-year-old children. Proceedings of the $26^{\text {th }}$ International Congress of Physical Education \& Sport Science, Komotini-Greece, 269-273.

AGA (2004) Arbeitsgemeinschaft Adipositas im Kindes- und Jugendalter Leitlinien. (Working group Obesity in childhood and adolescence. Guidelines) 10.9.2004 (in German). Available at UR: hhtp://www.a-g-a.de.

Alderman, B. L., Beighle, A., \& Pangrazi, R. P. (2006). Enhancing motivation in physical education. Journal of Physical Education, Recreation \& Dance, 77, 41-45. http://dx.doi.org/10.1080/07303084.2006.10597828.

Bournelli, P., Koutsouki, D., Zografou, M., Maridaki, M., Chatzopoulos, D., \& Agalianou, O. (2007). Physical education $\alpha^{\prime} \& \beta^{\prime}$ class primary school. Teacher's book. OEDB.

Centres for Disease Control (2004). United states life tables 2002. National Vital Statistics Reports, 53, 1.

Cheng, J., East, P., Blanco, E., Kang Sim, E., Castillo, M., Lozoff, B., \& Gahagan, S. (2016). Obesity leads to declines in motor skills across childhood. Child: care, health and development, 42(3), 343-350. https://doi.org/10.1111/cch.12336.

Cole, T. J., Bellizzi, M. C., Flegal, K. M., \& Dietz, W. H. (2000). Establishing a standard definition for child overweight and obesity worldwide: international survey. BMJ, 320, 1240-1243. https://doi.org/10.1136/bmj.320.7244.1240.

Cools, W., De Martelaer, K., Samaey, C., \& Andries, C. (2009). Movement skill assessment of typically developing preschool children: A review of seven movement skill assessment tools. Journal of Sports Science and Medicine, 8, 154-168. 
Chumlea, W. C., Knittle, J. L., Roche, A. F., Siervogel, R. M., \& Webb, P. (1981). Size and number of adipocytes and measures of body fat in boys and girls 10 to 18 years of age. The American Journal of Clinical Nutrition, 4(9), 1791-1797. https://doi.org/10.1093/ajcn/34.9.1791.

D’ Hondt, E., Deforche, B., Gentier, I., Verstuyf, J., Vaeyens, R., De Bourdeaudhuij, I., Philippaerts, R., \& Lenoir, M. (2014). A longitudinal study of gross motor coordination and weight status in children. Obesity, 22(6), 1505-1511.

D’ Hondt, E., Deforche, B., Gentier, I., De Bourdeaudhuij, I., Vaeyens, R., Philippaerts, R., \& Lenoir, M. (2013). A longitudinal analysis of gross motor coordination in overweight and obese children versus normal-weight peers. International Journal of Obesity, 37(1), 61-67. doi: 10.1038/ijo.2012.55.

Graf, C., Koch, B., Falkowski, G., Jouck, S., Christ, H., Stauenmaier, K. et al. (2005). Effects of a school-based intervention on BMI and motor abilities in childhood. Journal of Sports Science and Medicine, 4, 291-299.

Hagger, M., Chatzisarantis, N., \& Biddle, S. (2001). The influence of self-efficacy and past behaviour on the physical activity intentions of young people. Journal of Sports Sciences, 19(9), 711-725. doi: 10.1080/02640410152475847.

Hassapidou, M., Tzotzas, T., Makri, E., Pagkalos, I., Kaklamanos, I., Kapantais, E... \& Tziomalos, K. (2017). Prevalence and geographic variation of abdominal obesity in 7 and 9-year old children in Greece; World Health Organization childhood obesity surveillance initiative 2010. BioMed Central Public Health, 17(1), 126. doi: 10.1186/s12889-017-4061-x.

Holfelder, B., \& Schott, N. (2014). Relationship of fundamental movement skills and physical activity in children and adolescents: A systematic review. Psychol. Sport Exerc. $15,382-391$.

Janssen, I., Katzmaryk, P. T., Boyce, V. F., Vereeken, C., Mulvihill, C., Vereeken, C., Mulvihill, C., Roberts, C., Currie, C., \& Picket, W. (2005). Comparison of overweight and obesity prevalence in school-aged youth from 34 countries and their relationships with physical activity and dietary patterns. Obesity reviews, 6(2), 123-132. https://doi.org/10.1111/j.1467-789X.2005.00176.x.

Kavey, R. E., Daniels, S. R., Lauer, R. M., Atkins, D. L., Hayman, L. L., \& Taubert, K. (2003). American heart association guidelines for primary prevention of atherosclerotic cardiovascular disease beginning in childhood. Circulation, 107, 1562-1566.

Kioumourtzoglou, E., \& Derri, V. (2003). Aims, goals and pursuit in physical education. Forum: Physical Education, redefining its role. Ouranoupolis- Chalkidiki.

Kiphard, E., \& Schilling, F. (2007). Body coordination test for children. Weinheim, Beltz Test GmbH.

Kyriazis, I., Rekleiti, M., Saridi, M., Beliotis, E., Toska, A., Souliotis, K., \& Wozniak, G. (2012). Prevalence of obesity in children aged 6-12 years in Greece: nutritional 
behaviour and physical activity. Archives of medical science, 8(5), 859-864. doi: 10.5114/aoms.2012.31296.

Laukkanen, A., Pesola, A. J., Finni, T., \& Sääkslahti, A. (2017). Body mass index in the early years in relation to motor coordination at the age of $5^{-7}$ years. Sports (Basel, Switzerland), 5(3), 49. https://doi.org/10.3390/sports5030049.

Lopes, V. P., Rodrigues, L. P., Maia, J. A. R., \& Malina, R. M. (2011). Motor coordination as predictor of physical activity in childhood. Scand. J. Med. Sci. Sports, 21(5), 663-669, doi: 10.1111/j.1600-0838.2009.01027.x.

Lopes, V. P., Stodden, D. F., Bianchi, M. M., Maia, J. A. R., \& Rodrigues, L. P. (2012). Correlation between BMI and motor coordination in children. J. Sci. Med. Sport, 15, $38-43$.

Marmeleira, J., Veiga, G., Cansado, H., \& Raimundo, A. (2017). Relationship between motor proficiency and body composition in 6-to 10-year-old children. Journal of Pediatrics and Child Health, 53(4), 348-353. https://doi.org/10.1111/jpc.13446.

Martin, J., \& Kullina, P. (2004). Self-efficacy theory and the theory of planned behavior: Teaching physically active physical education classes. Research Quarterly for Exercise and Sport, 75(3), 288-297. https://doi.org/10.1080/02701367.2004.10609161.

Mond, J. M., Stich, H., Hay, P. J., Kraemer, A., \& Baune, B. T. (2007). Associations between obesity and developmental functioning in pre-school children: a populationbased study. International Journal of Obesity,31, 1068-1073. doi: 10.1038/SJ.IJO.0803644.

U.S. Department of Health and Human Services. (2008). physical activity guidelines for Americans. Washington, DC: U.S. Department of Health and Human Services.

Ruzbarska, I., Zvonar, M., Oleśniewicz, P., Markiewicz-Patkowska, J., Widawski, K., \& Puciato, D. (2016). Motor coordination and body mass index in primary school children. International Journal of Educational and Pedagogical Sciences, $10(11), 3555-3559$.

Schott, N., Alof, V., Hultsch, D., \& Meermann, D. (2007). Physical fitness in children with developmental coordination disorder. Research Quarterly for Exercise and Sport, 78(5), 438-450. doi: 10.5641/193250307X13082505158660.

Stodden, D., Langendorfer, S., \& Roberton, M. A. (2009). The association between motor skill competence and physical fitness in young adults. Research Quarterly for Exercise and Sport, 80(2), 223-229. doi: 10.1080/02701367.2009.10599556.

Tokmakidis, S., Bogdanis, G., Sindonis, L., Mougios, B., \& Mamen, A. (2000). Exercise and obesity. Exercise \& Society, 32, 5-21.

Trost, S. G., Kerr, L. M., Ward, D. S., \& Pate, R. R. (2001). Physical activity and determinants of physical activity in obese and non-obese children. International Journal of Obesity, 25(6), 822-829. doi:10.1038/sj.ijo.0801621. 
Tzetzis, G., Kakamoukas, V., Goudas, M., \& Tsorbatzoudis, C. (2005). A Comparison of physical activity patterns and physical self-perception in obese and non-obese children. Inquiries in Sport \& Physical Education, 3(1), 29- 39.

Vandorpe, B., Vandendriessche, J., Lefevre, J., Pion, J., Vaeyens, R., Matthys, S., Philippaerts, R., \& Lenoir, M. (2011). The Körperkoordinationstest für Kinder: Reference values and suitability for 6-12-year-old children in Flanders. Scandinavian Journal of Medicine \& Science in Sports, 21, 378-388. doi:10.1111/j.16000838.2009.01067.x.

Vandorpe, B., Vandendriessche, J., Vaeyens, R., Pion, J., Matthys, S., Lefevre, J., Philippaerts, R., \& Lenoir, M. (2012). Relationship between sports participation and the level of motor coordination in childhood: A longitudinal approach, Journal of Science and Medicine in Sport, 15(3), 220-225. https://doi.org/10.1016/j.jsams.2011.09.006.

U.S. Department of Health and Human Services. (2000). Healthy people 2010: Understanding and Improving Health. Washington, D.C. 